DE DE GRUYTER OPEN
Journal of Intercultural Management

Vol. 5, No. 4, December 2013, pp. 93-103 DOI 10.2478/joim-2013-0029

\author{
Anna Tarabasz
}

University of Lodz

\title{
The model and role of online communication in intercultural management
}

\begin{abstract}
Communication via the Internet, regardless use of available tools, contributed significantly in reduced time of data flow and feedback reception. This is particularly important in case of companies with a complex structure and branches around the world. Information is available here for almost ",at fingertips", 24 hours a day, 7 days a week, regardless the time zone. Internet has also shortened the distance between message sender and recipient - in the form of direct information exchange (i.e. email exchange), as well as simplified the issue of indirect reach (i.e. via social networking sites or online campaigns).

Although in literature of the subject many authors performed the analysis of mass communication models, but to no avail would seek for the flow chart strictly dedicated to the electronic exchange information. This article aims to present the model of online communication, drawing on best practices of mass communication and at the same time implementing components of the electronic promotion. The paper is also contributed to show the universality of such model application in the exchange of information within electronic means, which seems important in case of intercultural management.

Key words: online communication, e-communication model, the Internet in multicultural management, cross-cultural management, communication

\section{Introduction}

With the growing interest in globalization and workplace diversity, cross cultural management has today become an important element of organization and therefore requires adequate consideration. Due to previously mentioned increased globalization of working structures, today's managers need a more precise understanding of intercultural communication in an effective management strategy. According to findings of University of Notre Dame
\end{abstract}


academics [2013, online] managers shall proactively engage in communication skills assessment and make necessary adjustments in order to address the current needs of today's increasingly diverse workforce.

Within literature on the subject theissue of intercultural communication shall be viewed in two ways. The first approach puts emphasis on staff management within multinationals ${ }^{1}$ and thus, the fact that in acts of information exchange and managerial behavior differentiating factors (including the culture of the country, shared values and beliefs, behavior, language, way of speech, gesture, dress code, etc.) should be taken into account. The second approach focuses not around global companies, but customers served by them. And although herein also similar aspects, as in the previously described case, are taken into account, it must be remembered that communication is this approach has completely different character. It is not about efficient workflow, neither project management, nor motivating employees, but it is about informing, building relationship with the brand and pure sale $\&$ promotional activities.

Regardless which of the abovementioned measures kinds of intercultural communication is considered, consistent values should always be purity, precision and clarity of the content. This in turn is inextricably linked with consensus building and collaboration encouraging, while providing instant feedback.

In multiculturalism there are so many components so it seems that „more is there to divide, than to combine". Therefore every universal factor has the proverbial "weight in gold". It makes, that from a proper perspective, the chaos randomness of seemingly unrelated factors begins to emerge coherent and logical picture. This is similar to pieces of colored glass, which are connected through a suitable binder into form a harmonious stained glass or mosaic. Such linker is a matter of clear, synchronous and instant communication, available 24 hours a day and 7 days a week.

It is possible, due to the Internet as channel of mass communication, with all of its tools. They are used in various ways - from informational websites, that may be a source of knowledge about the company for customers and potential customers, by probably the most popular communication via e-mail (in strictly informative purposes, in the form of a typical business correspondence, as well as commercial mailings), and display forms (purely sale and promotion character) up to social media actions (set equal to relationship building, communication and promotional activities).

\footnotetext{
1 Assuming that it could be the case of two kinds of companies - first with headquarter in a European country or in the U.S., and branches across the world, or about multicultural corporations - companies with many cultures representatives, which inter alia H. Gullestrup $[2004$, s.3] indicates
} 


\section{Internet - a milestone for bidirectional communication}

However, there would be no question of all these tools, if not the very idea of electronic medium - the Internet. Turning point in the deliberations concerning mass communication is October the 1969 [Morley D. and Parker C.S., 2010, p. 322, Lambert L., 2005, pp. 16-17] and the moment of the new channel implementation, with the first message sent by the ARPAnet ${ }^{2 \square}$. Since then unilaterally sending remittances was ended, so did the possible backlash from traditionally passive audience.

New medium, that revolutionized mass communication, was established. According to D. L. Hoffman and T.P. Novak and P. Chatterjee [1995, online] Internet broke with classical one-to-many communication, depicting the oneway flow of information and signals within other mass media. It changed the paradigm of sender and recipient - individuals being source and destination of the message flow. The sender could be simultaneously the recipient, which until now was possible only as a sequence of particular events (receiver after receiving a message became the sender in order to give feedback). Here the phenomenon of information receipt and dispatch occurs at the same time, emphasizing additional advantages - low cost and virtually nil time of transmission.

Mass medium, such as the Internet, allows an immediate transition from the passive to the active state. The fact, that an individual is browsing the web in order to search for interesting information does not negate that in a moment it can begin the "active use" of this medium. This can occur by sending an e-mail or filling in the contact form, posting a post on the forum, or even reaching further activation: co-editing or full authorship of a website content [Tarabasz, A., 2012, p. 61]

Understood in this way communication via electronic media can play the binder role of this seemingly unrelated elements, which was mentioned in the article's introduction. For contemporary managers, managing within global enterprises, multicultural staff and acting for clients around the world, this channel of communication (regardless the tools used) is certainly very significant and valuable. Internet gives them, amongst others, the possibility of on-line brand management, all day access to visitor statistics, checking-todate sales results, but also, perhaps most importantly, the ability to contact 24/7 with customers and employees and from any location, regardless time zone. Moreover not to underestimate is the fact, that information posted in this medium, may be available literally "always and everywhere" (so-called transparency of Internet resources).

\footnotetext{
2 ARPAnet - Advanced Research Projects Agency Network, existing until today the first wide area network, based on distributed architecture and TCP / IP protocol. It is considered to be a direct ancestor of the Internet.
} 
All this allows managers, among others, fully synchronized launch of an advertising campaign, the possibility of immediate results monitoring and ongoing implementation of necessary patches. If given together the effectiveness of various marketing creations is verified on the basis of campaign results, quickly and easily changes could be made to ensure the action maximization. Simultaneously, new websites functionalities allow users to share particular site to the world in their native language, at no additional cost (due to on-line translators). Everything mentioned above, however, is the proverbial "tip of the iceberg" of online capabilities. Shall though not underestimated mail communication with employees in a different time zone, the fact of immediate alerts of coming correspondence, e-project management, videoconferencing, chats, instant messaging, etc... And all this is to allow for ongoing communication, faster, cheaper and easier than ever, almost at no extra cost and giving immediate feedback.

\section{In the search for a model of online communication}

Since the exchange of information by electronic means, regardless applied tools is so important in today's world and essential in the cross-cultural management, it was decided to formalize its flow diagram. Although the communication (in particular the mass-one) appears to be an idea relatively well described in the literature, it is difficult to find incorporation of the idea of communication via the Internet. Therefore, a verification of the existing schemes of mass communication in terms of relevance and direct application for e-reality was made. Unfortunately, in the course of conducted analysis of 12 mass communication models, it was found, that none of them was suitable for direct implementation in order to describe electronic communication with particular emphasis on online promotion. Therefore, it was decided to create such model, which, drawing on the best literature examples at the same time would be an attempt to expand on components absent from other models, which should, however, be taken into account in this study. In cross-sectional approach and view of very concise statement of schemes (cf. A. Tarabasz [2012, pp. 64-69]), it was found, that part of models cannot be taken into consideration, when creating original model of online communication. This are the models:

- Aristotle's art of rhetoric [1995, pp. 2152-2269],

- S. Tchakotine's mnipotence of propaganda [1952, pp. 40-70]

- H. Laswell's act of persuasion [1948, pp. 37-51]

- W. Schramm's interactive [1954, pp. 3-26]

- M.W. Riley and J.W. Riley's sociologic [1955, pp. 537-598]

- D.K. Berlo's S-M-C-R [1960, p. 72]

- G. Gerbner's perception of communication[1966, pp. 171-199]

Still, some of their components (such as the paradigm of sender and 
recipient, the issue of encoding, decoding, organization of content in a specific form and the idea of feedback) are necessary elements and should be included in own model. There is also a second category of schemes, which shall not be applied directly. These are the models:

- C. Shannon and W. Weaver's transmission of [Shannon C., 1948a, p.2; Shannon C., 1948b, pp.379-423, 623-656; Weaver W., 2008, pp. 27-38]

- K. Lewin's topologic [1947, pp. 143-153]

- E. Katz and P. Lazarsfeld's two-step flow of information [1955, pp. 60]

- R. Hiebert, D. Ungurait and T.W. Bohn's vawe HUB [1991, p. 72]

Lack of this possibility of "direct implementation" would mean the use of previously proposed model without making any modifications. But this should not occur, as these schemes do not take into account the complexity and the "technical side" of information flow between sender and recipient. However, there are elements (largely in common with those mentioned above), which should be used in proposed model. This means that none of the previously mentioned models does not meet the established requirements. It does not reflect the content flow complexity and potential feedbacks, does not take into account the "technical side" od described issues, and usually puts the receiver in the passive role of broadcasted content obtainer. Due to the 2.5-year participant observation ${ }^{3}$ it was confirmed, confirmed customers of institutions communicating its offer through the Internet do not remain passive recipients. They contact each other, consciously searching for deals, comparing and making a compilation of available information on presented offer. This underlies the need to formulate a new model of communication via the Internet, with particular regard to its narrower understanding of offer promoting.

Therefore, drawing from previously mentioned models of mass communication, the construction of own model was commenced, which could reflect the complexity of this phenomenon. At this point two things should be emphasized. First, although the proposed model aims to reflect dependence of communication between the company and its customers, however, in a broader sense, despite the apparent emphasis on promotion aspect, it also includes the idea of electronic information flow within the company itself (and thus refers to so called internal client). Secondly, despite the fact that in course of conducted research and participant observation, proposed model was built on the basis of polish banking sector, proposed solutions have utilitarian nature and can be (in the form of a diagram) implemented directly, and indirectly in

3 The author worked for BRE Bank SA as a web marketing specialist, e-commerce project manager, took part in reconstruction and reorganization project of information website of MultiBank 2.0, was responsible for sales, the consistency of the bank's image in the Internet channel, implemented included minisites, contenct designed for cooperating portals, such as Money.pl, Banker.pl, Onet.pl, Wirtualna Polska.pl, initiated promotional campaigns, worked with business lines and the marketing office of the bank in years 2005-2007. 
narrative form, used under pain of preserving adequacy of relevant activities.

The proposed model of on-line communication is built in subsequent stages, and therefore should be considered in such a manner in order to make it more readable and easier to receive. Institution (called the advertiser) decides to undertake an advertising campaign for a specific purpose (customer acquisition, establishing a closer relationship, reminding about the product or informing about changes). But recognizes, that wishing to communicate with Internet users, who are its current or potential clients, have access only to part of them. Therefore it cooperates with external company (also called an advertisement publisher; in analyzed case these were horizontal portals and sites cooperating with media houses), to which it outsources carrying out a paid advertising campaign with previously specified parameters ${ }^{4}$ after further brief ${ }^{5}$ preparation. After agreeing on cooperation terms, advertisement publisher proposes to advertiser a pecific mediaplan ${ }^{6}$, which after approval shall be implemented. At the same time the institution is preparing dedicated promotion webpage (so-called landing page), to which internet users clicking on the ad will redirect, regardless their source of acquisition.

It should be emphasized that the above description was simplified, as it was assumed that the entire external campaign is conducted by one company (advertisement publisher), who as the only has an adserver. Advertiser disposes only a server, on which promotional pages and landing page are created and to which all the campaign traffic is redirected. In addition, in order not to obscure information flow chart, it was assumed that institution in its internal operations decides only to use Internet, bypassing branches and customer service points, call center activity and other ways of product promotion (i.e. letter mailings, flyers, posters, outdoor etc.).

When an internet campaign is launched, usually synchronous all over the Web institution's advertising materials appear, issued by the advertiser and promoting company. An ongoing "battle for the customer" occursl within the real media zone of influence: newspapers, radio and TV. Designed along to previosu description graphical model of online communication is presented above (cf. Fig. 1).

4 Thus targeting of campaign is defined, which in advance specifies its target group.

5 Which acts as a plan of campaign. It concerns promoted product and its distinguishing features compared with its competitors, the target group, campaign duration, planned range, method of reaching, eventually planned use of promotional tools, etc.

6 Summary of on-line promotion tools used along with precise emission dates and quantification of impressions per unique user, campaign range and the prices of such action. 
Figure 1. The model of on-line communication

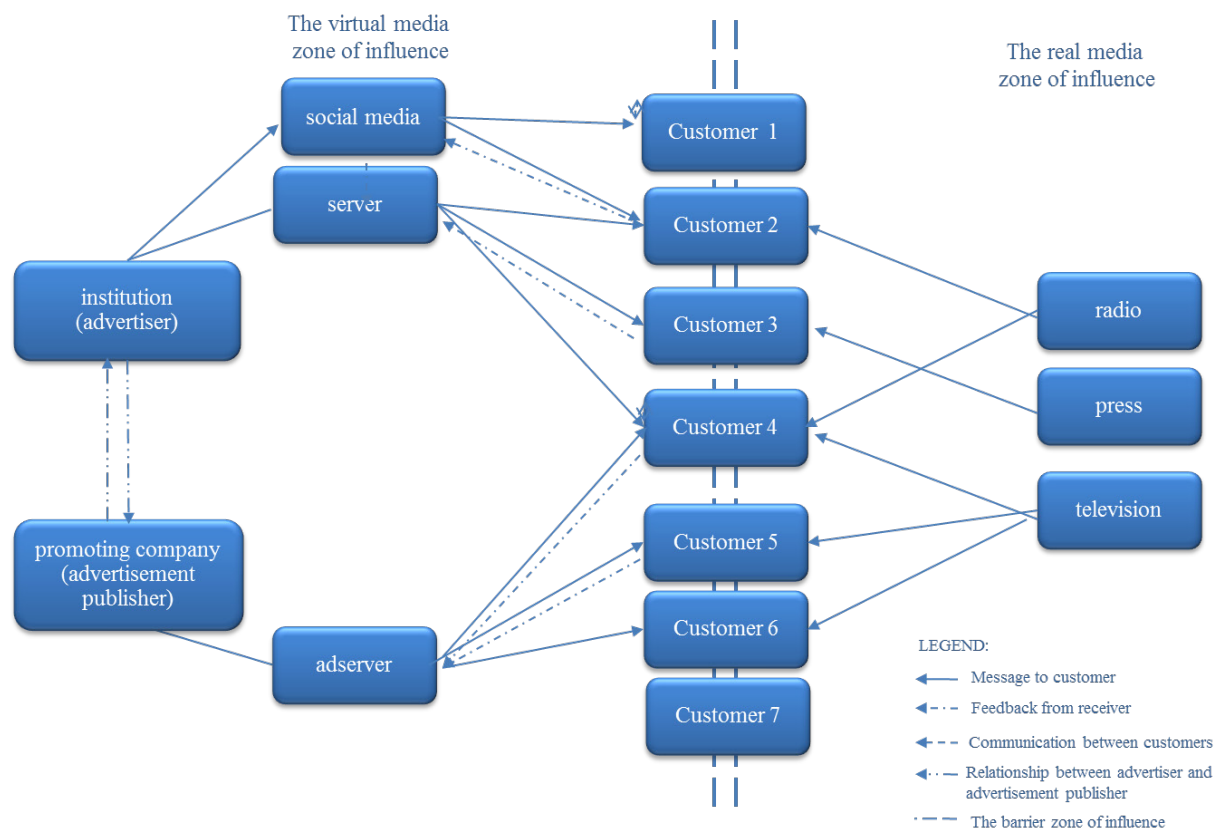

Source: Tarabasz, A., (2012) E-komunikacja na rynku ustug bankowych. Modele, narzędzia, zastosowanie, Łódź: Wydawnictwo Uniwersytetu Łódzkiego, p.71

At the launch of campaign both institution and advertisement publisher begin presenting promotional content, directing their messages to customers. It should be noted, however, that to a certain group of customers reaches only the advertiser (in the diagram visible as clients 2 and 3 ), to the other only an external company (customers 5 and 6). There are also customers groups that receive both promotional messages from different senders. But the most important connections are those between clients themselves ( 1 and 3, 4 and 6 ), and the social media impact. This is usually the exchange of information via e-mail, forums, chat rooms, within newsgroups or in the virtual community or by knowledge sharing on the blog. Once again, for simplicity, the schema assumes omitting the possibility of telephone and personal contacts between customers, replacing them with virtual forms of communication. Very important role, particularly in the informal channels of communication, should be thus noted , which the Internet plays seen not from the company's point of view, but its customers. Very often the latter provide an opinion on products, services and functionalities, recommending each other mentioned above factors. Thus, the 
Internet perceived in this way, becomes kind of "opinion superlider" through collective intelligence.

Particularizing social media tools, and isolating them from the whole package of electronic communication tools aimed at highlight their impact on communication with customers, and the interaction between them. In the course of conducted analysis it was found, that by adding social media tools, new connections between customers and the institution occurred (shown in the form of interaction between clients 1 and 3). Such action was also aimed at enhancing the flow of information between users. The procedure of implementation of this component was also resulting in emphasizing the importance of mutual interaction between customers and banks and thus, be an evidence of breaching the classic paradigm of one-way mass media communication. Interactivity available within social media tools is not only to facilitate contacts with the institution, but equally offers chance for a dialogue with the brand, its assessment and is the basis for relationships creation.

It is worth noting that despite the plethora of opportunities for contacts, obtaining knowledge, receiving messages from potential advertisers and advertisement emitters (so virtual and traditional), there is a group of customers who, although co-create target group of message transmission, remain out of reach (visualized as a client 7) most likely due to the lack of interest in such offer. To this group should also be included those, who theoretically had the opportunity to have contact with the message, but have not registered it in a conscious way (when the barrier of selective perception acted).

The descriptive part of the model has a much more complex character, as it is taking consideration the issues of responses to messages of a commercial and semi-advertising nature, as well as it rises the problem of total and partial feedback [cf. A. Tarabasz, 2012, pp.72-73.]. However, because these terms refer strictly to promotional activities idea, for the purposes of this article, it was decided to omit them, limiting the discourse only to highlighting the issue of the electronic messages transmission and presentation of the on-line communication model.

It should also be emphasized that the model of communication via the Internet presented here is not a purely theoretical. In light of participant observation results and on-line communication of largest banks in Poland activities analysis, it was decided on its empirical verification. It was done on the basis of:

- analysis of the available literature,

- available range of electronic communication tools,

- activities in the field of electronic communication of online banks,

- expertise of professionals actively taking part in building electronic 
communication in two of the surveyed banks, belonging to the retail branch of the BRE Bank Group (MultiBank and $\mathrm{mBank}^{7}$ ).

Once again, it is worth noting, that although empirical analysis of the model was made for the banking sector, there is no impediment to propose its implementation in other industries. It is appreciated that the proposed model has some imperfections - from the assumption it was deprived of certain elements and relationships between participants in the process in order to obtain its maximum clarity. In addition, the a priori assumption was made, that each message broadcasting is accompanied by the process of coding and for receiving - decoding. It is also anticipated that messages recipients (clients) share (at least partially) with communicating with them institutions and companies (within the community of experiences) language, culture, symbols and reality surrounding them, which results in fact, that the message sent does not deviate much from the information received. Despite such assumptions, proposed model is not a closed form and thus, is worth, future engagement in polemical discussion for its maximum improvement.

\section{Conclusion}

Communication is an integral part of human existence. Increasingly, interpersonal communication is done with the use of the most recent mass media - the Internet. It is fostered by many factors, the first of which appears to be steadily increasing number of its users - according to current data of Internet World Stats [2013, online] there are already more than 2.2 billion of internauts. Another are the advantages resulting from its electronic nature - the speed, immediacy, ease of feedback and full measurability. This medium is also a rich repository of knowledge about its users. Besides, not to be underestimated is the fact of the attractiveness of this audience to advertisers.

All this underlies the fact, that from a marketing point of view, more and more communication activities are based on electronic tools. However, the other side of the phenomenon is forgotten. This is not only a communication and promotional channel at the business-customer axe, but also medium of social communication, used largely for digital self-expression and entertainment. It is also mean of work, tool for effective management and business support solution in the inner aspect of its operation. It is mostly within the latter should be considered Internet and communication via it as an important aspect in the intercultural management. It provides managers with cheap, fast and direct contact with their subordinates; by definition reduces the separating distance and is also an extremely rich source of knowledge - so as an archive and as an information resource.

7 The $25^{\text {th }}$ of November 2013 the process of rebranding BRE Bank and MultiBank for mBank brand begun. Its end is planned for the year 2018 [ISB News, 2013, online] 
Therefore a reflection on the structuring and incorporation model of on-line communication was undertaken. These actions were based on cross-sectional analysis of the literature of the subject and its empirical verification based on expert knowledge, participant observation and activities of the largest banks in Poland in this regard. Nevertheless, the presented regularities are utilitarian and thus can be used to describe the activities in various industries and in a variety of capacities. This means not only the axe between the company and its customers, but also, which is of particular importance in intercultural management, in communication with corporate's internal customers.

\section{Bibliography}

Aristotle (1995) „Rethorics”, in Aristotle, (1995) Complete works, Princeton: Princeton University

Berlo, D.K. (1960) The process of communication, New York : Holt, Rinehart \& Winston

Gerbner, G. (1966) „Toward a General Model of Communication”, Audio-Visual Communication Review, vol. 4

Gullestrup H (2004), „The complexity of intercultural communication in cross-cultural management", Journal of Intercultural Communication, vol 6

Hiebert, R., Ungurait, D. and Bohn, T.W. (1991) An introduction to modern communication, New York: Longman, Goban-Klas, T. (1999) Media i komunikowanie masowe. Teorie i analizy prasy, radia, telewizji i Internetu, Kraków: PWN

Katz, E. and Lazarsfeld, P. Personal influence, New York: Free Press, quoted after GobanKlas, T. (1999) Media i komunikowanie masowe. Teorie i analizy prasy, radia, telewizji i Internetu, Kraków: PWN

Lasswell, H. (1948) „The structure and function of communication in society”, in Bryson L. (ed.) The communication of ideas, New York: Institute for Religious and Social Studies

Lewin, K. (1947), „Channels of group life”, Human Relations, vol. 1

Morley, D. and Parker, C.S. (2010) Understanding Computers: Today and Tomorrow, Course Technology Cengage Learning, Boston, p. 322

Riley, M.W. and Riley, J.W. (1955) „Mass communication and the social system”, in: Merton, R. Sociology today, New York: Basic Books

Schramm, W. (1954) How Communication Works. The Process and Effects of Communication, Urbana: University of Illinois Press

Shannon, C. (1948a) A mathematical theory of communication, Ilinois: Urbana University of Illinois

Shannon, C. (1948b) „A mathematical theory of communication”, The Bell System Technical Journal, vol. 27

Tarabasz A., (2012) E-komunikacja na rynku ustug bankowych. Modele, narzędzia, zastosowanie, Łódź: Wydawnictwo Uniwersytetu Łódzkiego

Tchakotine, S. (1952) Le viol de foules par la propagande politique, Paris: Gallimard, 
quoted after Volkoff, V. (2004) La désinformation. Arme de guerre, Paris: Editions l'Aged' Homme, pp. 40-70

Weaver, W. (2008 ) „The mathematics of communication”, in Mortensen, C.D. (ed.) Communication theory, New Jersey: Transaction Publishers

Helen Spencer-Oatey, Achieving Mutual Understanding for Effective Intercultural Management, [Online], Available: http://www2.warwick.ac.uk/fac/cross_fac/ globalpeople/resourcebank/researchpapers/mgtmutualunderstanding_v2.pdf [23 Dec 2013]

Hoffman, D.L., Novak, T.P. and Chatterjee, P., (1995) „Commercial Scenarios for the Web: Opportunities and Challenges", Journal of Computer-Mediated Communication, vol. 1, no. 3, [Online], Available: http://jemc.indiana.edu/vol1/issue3/hoffman.html[23 Dec 2013]

Internet World Stats, [Online], Available: http://www.internetworldstats.com/stats.htm [23 Dec 2013]

ISB News, BRE Bank i MultiBank pod szyldem mBanku już od 25 listopada, [Online], Available: http://serwisy.gazetaprawna.pl/finanse-osobiste/artykuly/743042,bre-bank-imultibank-pod-szyldem-mbanku-juz-od-25-listopada.html [31 Oct 2013]

University of Notre Dame Mendoza College of Business (2013), Intercultural Communication in the Global Workplace, [Online], Available: http://www. notredameonline.com/resources/intercultural-management/interculturalcommunication-in-the-global-workplace/\#.Utz9LPStaIU [20 Dec 2013] 